\title{
Chemotaxonomic Study Based on Flavonoids as Taxonomic Markers in the Roots of the Selected Species Belonged to Family Solanaceae, Sudan
}

\author{
Asaad Ahmed, Abdelgabbar Guma'a \\ Department of Chemistry, Imperial University College, Khartoum, Sudan \\ Email: asaadalsiddig@yahoo.com
}

How to cite this paper: Ahmed, A. and Guma'a, A. (2019) Chemotaxonomic Study Based on Flavonoids as Taxonomic Markers in the Roots of the Selected Species Belonged to Family Solanaceae, Sudan. American Journal of Plant Sciences, 10, 2298-2304. https://doi.org/10.4236/ajps.2019.1012160

Received: November 9, 2019

Accepted: December 24, 2019

Published: December 27, 2019

Copyright $\odot 2019$ by author(s) and Scientific Research Publishing Inc. This work is licensed under the Creative Commons Attribution International License (CC BY 4.0).

http://creativecommons.org/licenses/by/4.0/

c) (†) Open Access

\begin{abstract}
This work is a taxonomic study on flavonoids in the roots of selected species belonged to family Solanaceae. These species considered as: Lycopersicum esculentum, Solanum melongena and Solanum tuberosum. These species distributed in different localities in Sudan. The selected members have nutritive, medicinal and economic importance, extra of that, the present study included botanical and chemical studies. The collected species have been updated due to nomenclature and synonymy. The geographical distribution of the selected members has been indicated. The chemical studies included identification of the flavonoid compounds using Gas Chromatography Mass Spectrophotometer (GC-MS). Eighty-three flavonoid compounds were detected in the roots of family Solanaceae. The highest number (32) was detected in the roots of Solanum tuberosum. A single flavonoid compound was restricted only to the roots of Solanum melongena. This was: (cyclohexanol-5-methyl-2-(1methylene), \{1R-1.alpha, 2beta, 5.alpha\}). Four taxonomic markers were identified for the roots of Lycopersicum esculentum. Ten taxonomic markers were identified in the roots of Solanum tuberosum.
\end{abstract}

\section{Keywords}

Chemotaxonomy, Medicinal Plant, Sudan

\section{Introduction}

Flavonoids or bioflavonoids mean yellow in Latin language with reference to their colour in nature and they represent the plant secondary metabolites. Flavonoids are poly phenolic compounds possessing (15) carbon atoms with a leaner three-carbon chain. They also constitute one of the most characteristic 
classes of plant compounds. Flavonoids are easily recognized as "flower pigment" in the most angiosperm plant families [1]. However, their occurrence is not restricted to flowers but included all the parts of plants [2]. This compiled by Johns et al. [3]. The flavonoids have many classes such as chalcone, flavones, flavanones, flavanoles, anthocyanidins and isoflavonoids [4]. These are synthesized by the plants beside (4000), other compounds identified by their food sources [5]. The flavonoids may contribute to some of the health benefits associated with diets rich in fruit and vegetable [6]. Offering a wide range view of these classes of plant pigments after a brief examination of history and literature of flavonoid, there were sub-classes of flavonoids using multiple techniques for isolation, purification and determination of structures [7].

\section{Study Area}

The study conducted in the following localities in Sudan:

South Kordofan state (Western Sudan) lies between latitude $11^{\circ}-37.96^{\prime} \mathrm{N}$ and longitude $29^{\circ}-42^{\prime} \mathrm{E}$. Blue Nile State lies between latitude $11^{\circ}-09^{\prime} \mathrm{N}$ and longitude $34^{\circ}-06^{\prime} \mathrm{E}$ and khartoum lies between latitude $15^{\circ}-33^{\prime} \mathrm{N}$ and longitude $32^{\circ}$ - 31E. North Kordofan climate characterized as hot days and cold nights, sunny and partly clouds with relatively short rainy seasons. The area of the study mostly sand of yellowish red sandy loam. Blue Nile state climate depended on change of seasons and with result in a likely decline in stream flow which increases the soil moisture. Khartoum state climate change characterized as temperatures are rising, soil fertility is low and wind blows dusty and also mostly desert with receive barely rainfall.

\section{Population}

According to ethno-botanical, South Kordofan is an interesting state; it includes several people such as Arabs and Africans. The tribes in this state depend on (millet, sorghum, groundnuts and sesame) for nutrition, also their activities characterized as pastoral (cattle and goats). Blue Nile state is host to round forty different ethnic groups, its economic activity based on agriculture and livestock and increasing mineral exploitation while Khartoum state composed of various tribes distributed in many localities, most of population works in government services, private sectors and banking. Khartoum represents the capital city because it contains governmental and non-governmental organizations and also include the main airport.

\section{Methodology}

\subsection{Plant Material}

The plants of the selected species from this family were collected from different localities in Sudan, Solanum melongena and Lycopersicum esculentum were brought from Blue Nile state and Solanum tuberosum species were brought from Khartoum state (Table 1). The plants were identified and their root was 
chemically analyzed by using gas chromatography-mass spectrophotometry (GC-MS), this instrument uses to analyze and identify the components found in the selected plant part (roots) (Table 2). The version of this system is (GC-MS QP 2010 plus) which works as coupled system to separate and identify the components. A cyclic ring made of cupper was used as stationary phase while the carrier gas (Helium) was used as mobile phase. The (GC) apparatus was configured by adjusting temperature, pressure and time and (MS) identified the components. The (GC-MS) was integrated composite analysis to separate and quantify the contents.

\subsection{Preparation of the Plant Material}

The plant material was washed throughly with running tap water, followed by rinsing with distilled water then air-dried, after that the roots get dried and

Table 1. Medicinal applications of the roots of the selected species of plant family Solanaceae in Sudan.

\begin{tabular}{ccccc}
\hline $\begin{array}{c}\text { Scientific name/Family/ } \\
\text { Local name/syn. }\end{array}$ & $\begin{array}{c}\text { Part } \\
\text { used }\end{array}$ & Uses/Ailments/Treated & $\begin{array}{c}\text { Preparations/ } \\
\text { Administrations }\end{array}$ & Locality \\
\hline $\begin{array}{c}\text { Solanum melongena (L.) } \\
\text { Solanaceae }\end{array}$ & Roots & $\begin{array}{c}\text { Reduce cholesterol levels } \\
\text { Eggplant and aubergines }\end{array}$ & Infusion & Alsereio \\
$\begin{array}{c}\text { Lycopersicum esculentum (L.) } \\
\text { Solanaceae } \\
\text { Tomato }\end{array}$ & Roots & $\begin{array}{c}\text { Decrease the risk of breath } \\
\text { cancer and also head and } \\
\text { neck cancer. } \\
\text { Reduce cardiovascular }\end{array}$ & Infusion & Alsereio \\
$\begin{array}{c}\text { Solanum lycopersicum (L.) } \\
\text { Solanum tuberosum (L.) }\end{array}$ & & Roots & Antioxidant as major & Infusion \\
Solanaceae & & Al Nuba \\
Potato & & & & \\
\hline
\end{tabular}

Table 2. Pairing affinity between the studied members of family Solanaceae based on the selected flavonoids in the roots.

\begin{tabular}{ccc}
\hline Species & Flavonoid compounds & Pairing affinity (Roots) Index (PA \%) \\
\hline Between S. melongena and & Esters & $33.3 \%$ \\
L. esculentum & Ethers & $37.5 \%$ \\
& alkenes & $0 \%$ \\
& Alkanes & $25 \%$ \\
Between L. esculentum and & Aldehydes & $40 \%$ \\
S. tuberosum & Esters & $33.3 \%$ \\
& Ethers & $40 \%$ \\
Between S. melongena and & Alkanes & $33.3 \%$ \\
S. tuberosum & Aldehydes & $25 \%$ \\
& Alkyles & $50 \%$ \\
& Esters & $31.6 \%$ \\
& Ethers & $20 \%$ \\
& Alkynes & $50 \%$ \\
& Alkanes & $0 \%$ \\
& Aldehydes & $33.3 \%$ \\
\hline
\end{tabular}


manually ground. The powder of the roots was then passed into sieves of different sizes (Retsch, German).

\subsection{Preparation of the Crude Extracts}

One ml. of methanol (70\%) was added to (1) gm. of the powdered roots. The solution was then injected into (GC) while (MS) detected and identified the components.

\subsection{Data Analysis}

All the data illustrated have been integrated and analyzed see (Table 2). The results have been structed according to these categories: number of plant mentioned with (scientific names, botanical families and vernacular names). The references were complete in central laboratory. Study of quantitative was also performed using frequency per species and was estimated by calculation of the plant sites.

\section{Discussion}

The data detected in this study were compared with the related literature and also published reports on the traditional medicinal uses of the plants. The species named as: Lycopersicum esculentum, Solanum melongena and Solanum

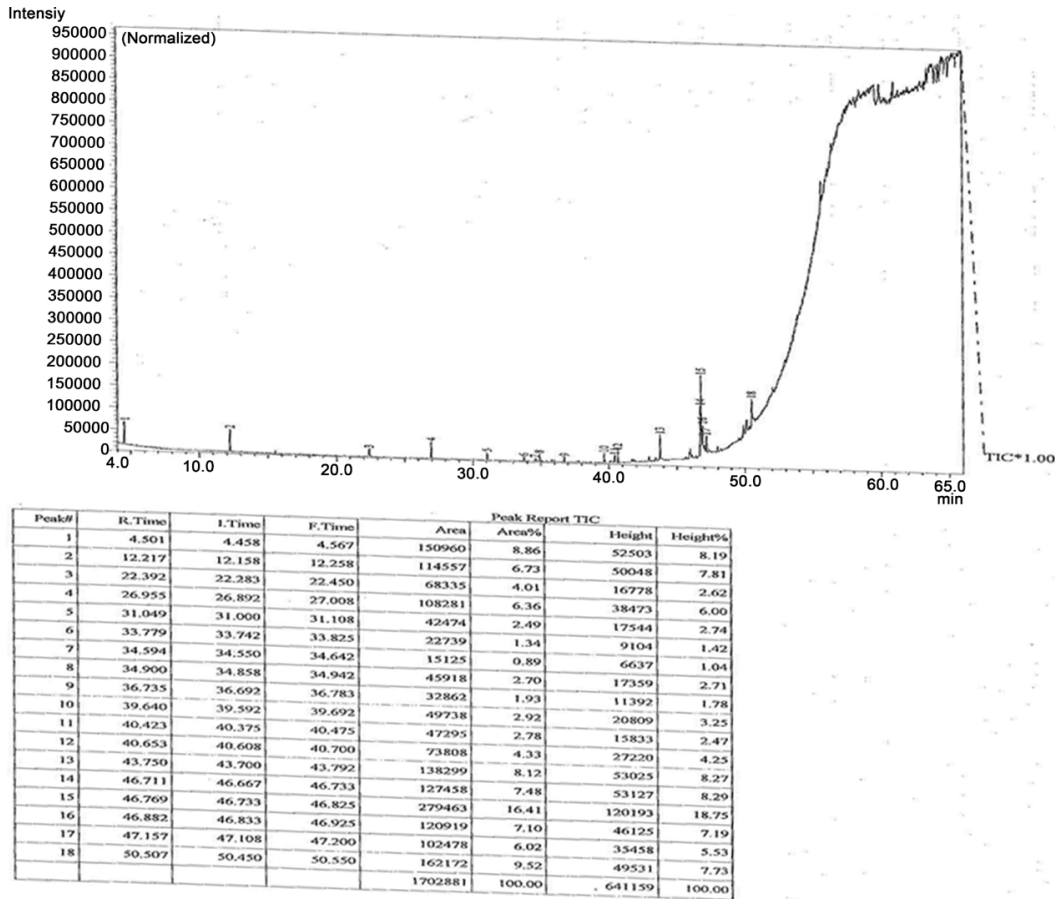

Abbreviations and formulae of calculation: $\mathrm{R}$. time $=$ retention time. $\mathrm{I}$. time $=$ initial time. F. time $=$ full time. $\%$ area $=\frac{\text { area of peak }}{\text { Total area }} \times 100 \%$. \% height $=\frac{\text { height of peak }}{\text { Total height }} \times 100 \%$. TIC $=$ (total ions chromatography).

Figure 1. The relationship between time and intensity of fragmentation which induced peaks in the roots of Lycopersicum esculentum. 


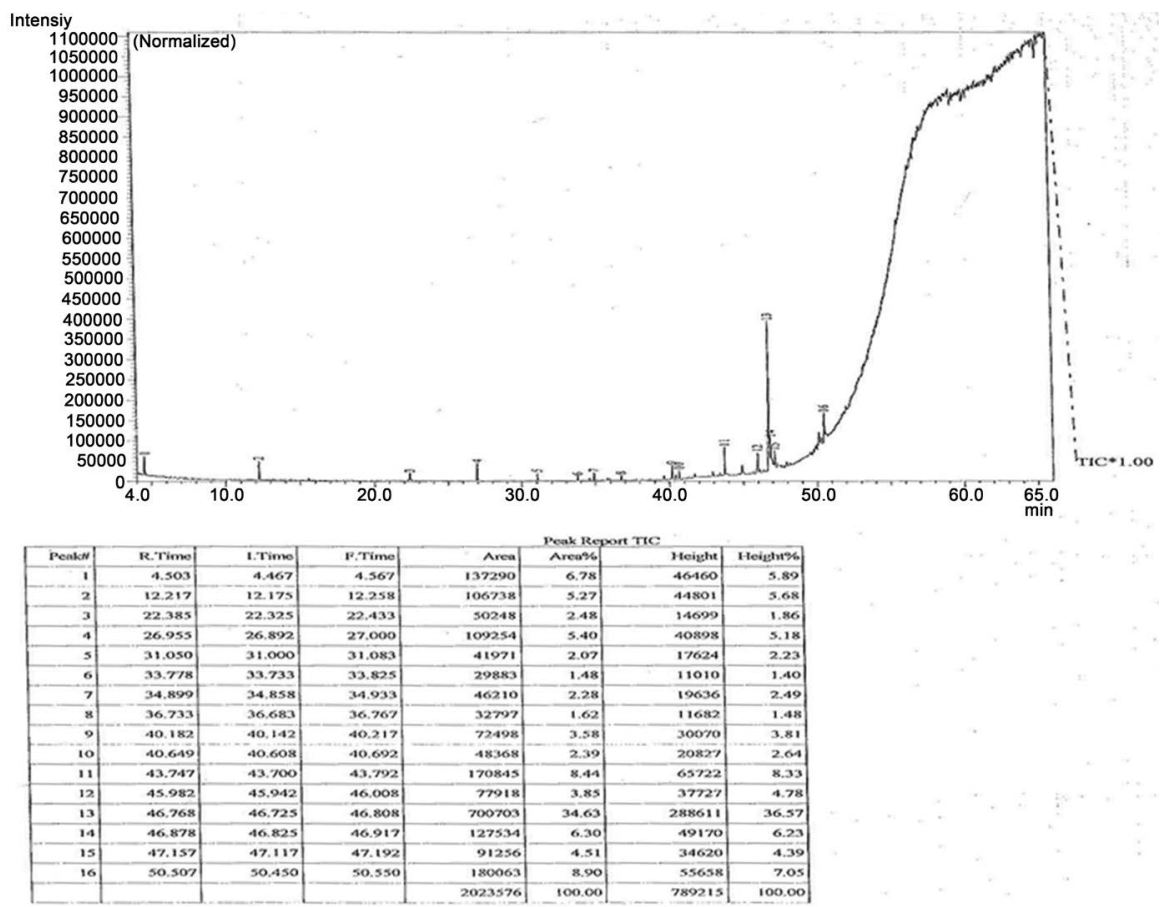

Abbreviations and formulae of calculation: R. time $=$ retention time. I. time $=$ initial time. F. time $=$ full time. $\%$ area $=\frac{\text { area of peak }}{\text { Total area }} \times 100 \% . \%$ height $=\frac{\text { height of peak }}{\text { Total height }} \times 100 \%$. TIC $=($ total ions chromatography).

Figure 2. The relationship between time and intensity of fragmentation which induced peaks in the roots of Solanum melongena.

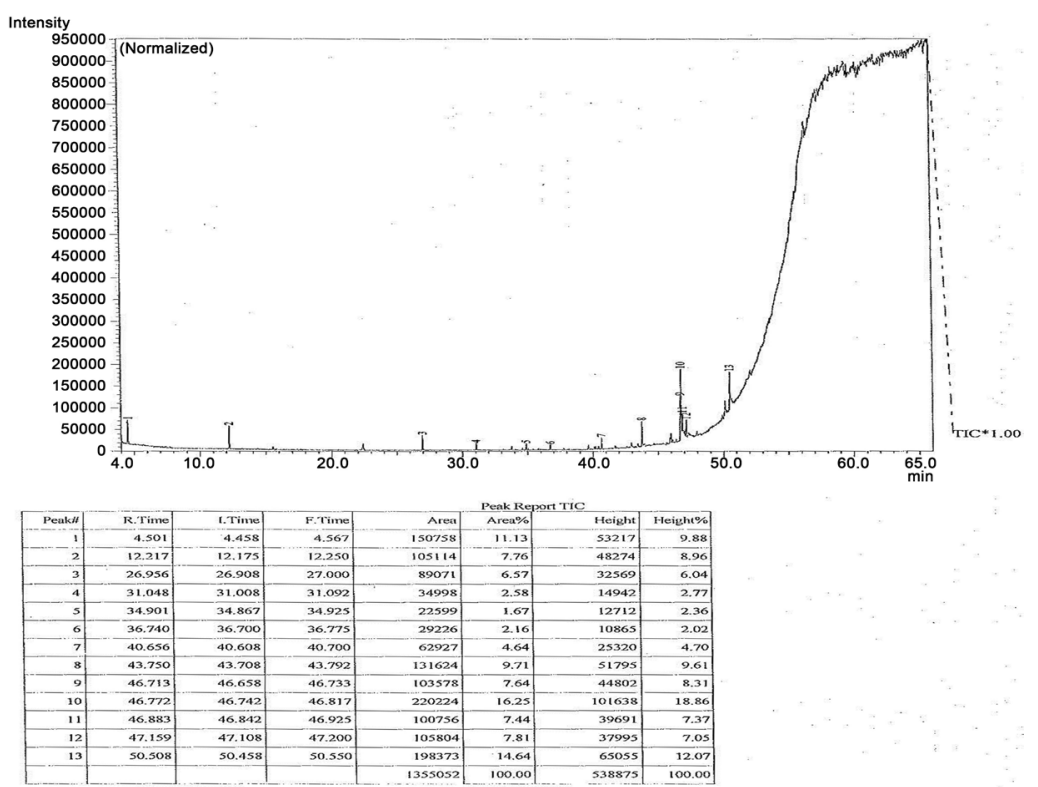

Abbreviations and formulae of calculation: $\mathrm{R}$. time $=$ retention time. I. time $=$ initial time. $\mathrm{F}$. time $=$ full time. $\%$ area $=\frac{\text { area of peak }}{\text { Total area }} \times 100 \% . \%$ height $=\frac{\text { height of peak }}{\text { Total height }} \times 100 \%$. TIC $=($ total ions chromatography).

Figure 3. The relationship between time and intensity of fragmentation that induced peaks in the roots of Solanum tuberosum. 
tuberosum. The selected parts were roots. The number of the flavonoid compounds of the selected members of family Solanaceae in the roots were (83) compounds. The flavonoid compounds kaempferol and quercetin were reported by many authors in many species such as William et al. [8], Buttery et al. [9], Chil [2] and Ojong et al. [10]. This result was not confirmed in the present study. The number of the flavonoid compounds in the roots of Lycopersicum esculentum were (31) (Figure 1), the numbers of the flavonoid compounds in the roots of Solanum melongena were (20) (Figure 2) and the number of the flavonoid compounds in the roots of Solanum tuberosum were (32) (Figure 3). Some authors Barceloux [11]; Slimested et al. [12] reported the occurrence quercetin and kaempferol in the fruits of Lycopersicum esculentum but not in the roots of this species. The flavonoid compounds 9-octadecenal, $(\mathrm{Z})$ and lauric acid chloride occurred only in the roots of Solanum melongena [1]. Donatus et al. [13] detected the flavonoid 9-octadecenoic acid-1,2,3-propanetriy ester E,E,E. this was reported in the present study.

\section{Conclusion}

Roots are preferred because of their high flavonoid contents, it can be prepared in daily meals since some of components have many benefits as strengthening muscles, antioxidant and antifungal. The modern health care services in South Kordofan and Blue Nile are not adequate because of few care centers and hospitals and most people cannot afford to buy drugs prescribed due to their low income. Roots of the selected members of family Solanaceae were recommended because of their high medicinal contents. Due to this information flavonoids can be used as antifungal, antibacterial, antiviral and strengthen of muscles beside antioxidants to prevent the most types of cancers.

\section{Acknowledgements}

The author is very grateful to the laboratorists in the central laboratory for sharing their knowledge through this study.

\section{Conflicts of Interest}

The authors declare no conflicts of interest regarding the publication of this paper.

\section{References}

[1] Braz, J.N. (2000) Eggplant (Solanum melongena) Infusion Has a Modest and Transiteny Effect on Hybercholestrolemic Subject. Brazilian Journal of Medical and Biological Research, 33, 1027-1036. https://doi.org/10.1590/S0100-879X2000000900006

[2] Chil, J. and Soc, C. (2009) Chemotaxonomic Significance of Flavonoids in Solanum nigrum Complex. Journal of the Chilean Chemical Society, 54, 486-490. https://doi.org/10.4067/S0717-97072009000400037

[3] Johns, W.P. and Douglas, A. (2005) Extraction of Plant Secondary Metabolites. National Products Isolation, 20, 323-351. https://doi.org/10.1385/1-59259-955-9:323 
[4] Vula, B., Wang., W.H., Rumalla, C.S., Smillie, T.J., Wester, D.E., Kim, C.H. and Khan, I.A. (2011) Rapid Analysis of Phenolic Acids, Flavonoids and Sterols in Commercial Extract of Taraxacum officinale Leaves and Roots Using HPLC-UV-ELSD/MS. Planta Medica, 8, 73-77. https://doi.org/10.1055/s-0031-1273602

[5] Ayaz, A.M., Nagma, M., Dvanand, L.L., Mohammed, I.B. and Amanat, A.B. (2009) Phenolic Acids, Profiling and Antioxidant Potential of Mulberry Morus laevigata, Morus nigra and Morus alba. 60, 25-32.

[6] Farooq and Mohammed, N. (2010) Okra (Hibiscus esculentus) Seed Oil for Biodiesel Productions. Applied Energy, 87, 785-779. https://doi.org/10.1016/j.apenergy.2009.09.020

[7] Wilkomirsk, B., Dubielecka, B. and Mazan, D. (1998) Significant of the Flavonoid Levels in the Phonetic Taxonomy of the Genus Betula. Plant Biosystems-An International Journal Dealing with all Aspects of Plant Biology, 132, 138-233. https://doi.org/10.1080/11263504.1998.10654207

[8] Williams, C.A., Richardson, J., Greenham, J. and Eagles, J. (1993) Correlation between Leave Flavonoids, Taxonomy and Plant Geography in the Genus Disporum. Phytochemistry, 34, 197-203. https://doi.org/10.1016/S0031-9422(00)90805-7

[9] Buttery, B.R. and Buzzell, R.I. (1973) Varietal Differences in the Leaf Flavonoids of Soybeans. 13, 103-106.

[10] Ojong, P.B., Nijiti, V., Guo, Z., Gao, M., Besong, S. and Barnes, S.L. (2008) Variation of Flavonoid Contents among Sweet Potato Accessions. Journal of the American Society for Horticultural Science, 133, 819-824. https://doi.org/10.21273/JASHS.133.6.819

[11] Barceloux, D.G. (2009) Potatoes, Tomatoes and Solanine Toxicity. Disease-a-Month, 55, 391-402. https://doi.org/10.1016/j.disamonth.2009.03.009

[12] Slimested, R., Fossen, T. and Verheul, M.J. (2008) The Flavonoid of Tomatoes. Journal of Agricultural and food Chemistry, 56, 41-2436. https://doi.org/10.1021/jf073434n

[13] Donatus, E.O. and Benson, U.I. (2012) GC-MS Evaluation of Bioactive Compounds and Antibacterial Activity of the Oil Fraction from the Leaves of Alstonia boonei De Wild. Journal for Medicinal Chemistry, Pharmaceutical Chemistry, Pharmaceutical Sciences and Computational Chemistry, 2, 261-272. 